\title{
CXCL12/CXCR4-axis dysfunctions: Markers of the rare immunodeficiency disorder WHIM syndrome
}

\author{
Françoise Bachelerie* \\ Pathogénie Virale, Inserm U819, Institut Pasteur, 25-28 rue du Dr Roux, 75015 Paris, France
}

\begin{abstract}
The WHIM syndrome features susceptibility to human Papillomavirus infection-induced warts and carcinomas, hypogammaglobulinemia, recurrent bacterial infections, B and T-cell lymphopenia, and neutropenia associated with retention of senescent neutrophils in the bone marrow (i.e. myelokathexis). This rare disorder is mostly linked to inherited heterozygous autosomal dominant mutations in the gene encoding $C X C R 4$, a $\mathrm{G}$ protein coupled receptor with a unique ligand, the chemokine CXCL12/SDF-1. Some individuals who have full clinical forms of the syndrome carry a wild type CXCR4 gene. In spite of this genetic heterogeneity, leukocytes from WHIM patients share in common dysfunctions of the CXCR4-mediated signaling pathway upon exposure to CXCL12. Dysfunctions are characterized by impaired desensitization and receptor internalization, which are associated with enhanced responses to the chemokine. Our increasing understanding of the mechanisms that account for the aberrant CXCL12/CXCR4-mediated responses is beginning to provide insight into the pathogenesis of the disorder. As a result we can expect to identify markers of the WHIM syndrome, as well as other disorders with WHIM-like features that are associated with dysfunctions of the CXCL12/CXCR4 axis.
\end{abstract}

\section{Introduction}

Chemokines are classically referred to as small cytokines that regulate the directional migration (i.e. chemotaxis) of leukocytes toward a concentration gradient. This process occurs through interaction with receptors that belong to the $\mathrm{G}$ protein-coupled receptor (GPCR) superfamily, during normal and pathological conditions [1]. The chemokine superfamily encompasses 47 members, which are divided into two major subfamilies (CXC, CC) and two other subfamilies $(\mathrm{C}, \mathrm{CX} 3 \mathrm{C})$, based upon the arrangement of the two $\mathrm{N}$-terminus cysteine residues [2]. Chemokines/chemokines receptors display a high degree of conservation throughout evolution from jawless fish to humans, and this system is critical for the proper development and function of many tissues in vertebrates.

${ }^{*}$ Corresponding author. Tel.: +33 (0) 406 13467; Fax: +33 (0) 456 88941; E-mail: fbachele@pasteur.fr.
Although chemokines and their receptors generally display redundancy and binding promiscuity, some chemokines play pivotal and non-redundant homeostatic roles. A singular instance is the CXCL12/SDF-1 chemokine [3] and its receptor CXCR4 [4]. Targeted disruption of either CXCL12 or CXCR4 gene is lethal during mouse embryogenesis and leads to many defects including impaired B-cell lymphopoiesis and bonemarrow (BM) myelopoiesis and hematopoiesis [5-7]. The CXCL12 chemokine, which is constitutively expressed in the BM, plays a prominent role in the retention of BM neutrophils, by tightly controlling their release into the blood and their clearance from the circulation during normal and inflammatory conditions [8]. For instance, rapid mobilization of neutrophils from $\mathrm{BM}$ is observed upon treatment of mice with granulocyte-colony-stimulating factor, which reduces BM CXCL12 levels [9]. Similar observations are seen following treatment of humans or mice with the CXCR4 antagonist AMD3100 [10,11]. The CXCL12/CXCR4 axis also modulates the trafficking of 
B-cells within peripheral lymphoid organs during their differentiation and activation $[12,13]$ and the release of mature B-lymphocytes from BM [14].

The CXCR4 chemokine receptor was originally described as a co-receptor for Human Immunodeficiency Virus entry [4] and CXCL12 as a potent inhibitor of infection through internalization of the receptor or competitive inhibition of the viral envelope binding $[15,16]$. Dysregulation of the CXCL12/CXCR4 axis was subsequently shown in cancer metastasis [17] and more recently in a rare combined immunodeficiency disorder known as WHIM syndrome [18]. WHIM syndrome was reported in the early 1960's as an unusual form of congenital neutropenia associated with hyperplasia of mature neutrophils in the BM, termed myelokathexis [19]. The WHIM syndrome derives its acronym from the clinical manifestations of Human Papillomavirus Virus (HPV)-induced Warts, Hypogammaglobulinemia, bacterial Infections, and the pathognomonic Myelokathexis [20]. A marked lymphopenia, which affects both T- and B-lymphocytes, completes the picture.

The clinical onset and complications in WHIM are more variable than originally suspected with the notable exceptions of neutropenia and lymphopenia, which are always observed in patients suffering from this disorder. However, most of the reported patients present with myelokathexis and suffer from an unusual and selective susceptibility to HPV infection (92\% and 79\%, respectively (for review; [21,22] and [23-26]). HPV pathogenesis in patients manifests as profuse and persistent cutaneous warts. In some adults, intractable genital condyloma acuminata often progress to severe dysplasia and carcinoma and are significant cause of premature mortality.

BM abnormalities are the most prominent features that not only distinguish the WHIM-associated neutropenia from other congenital neutropenia, but also can explain why WHIM patients suffer from relatively few bacterial infections. Indeed, the BM neutrophils can be mobilized during infections and upon granulocyte - macrophage colony-stimulating factor administration, thus resulting in transient normalization of BM cytology and peripheral neutrophil counts [27-29]. These observations support the seminal hypothesis that neutropenia arises from disturbed cell trafficking.

In line with this, the recent discovery that an increased activation of the CXCL12/CXCR4 axis is a biological feature of the WHIM syndrome has opened up promising leads for understanding disease pathogenesis [18]. In many cases of WHIM syndrome, dys- functions of the CXCL12/CXCR4 signaling axis were found to be linked to inherited heterozygous autosomal dominant mutations in the gene encoding CXCR4 [18]. The relevance of these observations to pathogenesis was fully appreciated when a similar pattern of dysfunctions was observed in patients carrying a wild type CXCR4 ORF [23]. Thus, altered CXCL12/CXCR4mediated signaling constitutes a common biologic trait of WHIM syndrome with different genetic causes.

The clinical features, diagnosis and management of the WHIM syndrome, which is considered to be the first example of a human disorder mediated by dysfunction of a chemokine receptor, have been recently reviewed [21,22,30-32]. I will therefore restrict my comments to the dysregulation of the CXCL12/CXCR4signaling axis, after reviewing current knowledge about the regulation of this axis.

\section{Regulation of CXCL12/CXCR4-dependent signaling}

\subsection{CXCL12/CXCR4 interactions}

Chemokines signal by engaging cognate receptors that belong to class A of the GPCR superfamily. The structural basis of class A GPCR-mediated signal transduction is mostly extrapolated from crystal structures of rhodopsin [33] and more recently of the human $\beta$ adrenergic receptor [34,35]. Although these two paradigmatic examples display low sequence homology with chemokine receptors, they share striking basic features. There is a core of seven transmembrane helices (TM), which connects three extracellular and intracellular loops to an $\mathrm{N}$-terminus extracellular domain and a C-terminus intracellular domain. CXCL12 displays the typical chemokine structure with an unstructured $\mathrm{N}$-terminus, followed by a flexible N-loop, a threestranded anti-parallel $\beta$-sheet, and an $\alpha$-helix [36-38].

Although both the $\mathrm{N}$-terminus and the $\mathrm{N}$-loop were implicated in receptor binding [36,38,39], mutational analyses have revealed the importance of the Nterminus of the chemokine for triggering receptor activation [36]. Interactions between CXCL12 and CXCR4 were hypothesized to take place following a twostep binding process in which the docking site first involves the N-loop of CXCL12 (residues 12-17) and the $\mathrm{N}$-terminus of CXCR4, and then the first eight residues of the N-terminus of CXCL12 and buried residues in the TM helices of CXCR4 [36]. This model was supported by data obtained from CXCR4 chimeras and 
mutants [40-42] and a nuclear magnetic resonance (NMR) study of CXCR4 fragments associated with dimeric CXCL12 [43]. Moreover, recent findings provide structural evidence that the initial docking of CXCL12 takes place independently of its binding to the receptor TM region, which triggers receptor conformational changes and activation. Consequently, addition of AMD3100 that binds to the CXCR4 TM region [44, 45] promotes the release of the $\mathrm{N}$-terminus of CXCL12 from CXCR4, while the N-loop of the chemokine remains bound to the receptor [46].

\subsection{CXCL12/CXCR4-induced signaling}

GPCRs control numerous physiological and pathological processes and so represent important drug targets. Signaling through GPCRs appears more diverse than originally suspected. Signals can be modulated by a number of factors such as the existence of multiple active conformation states for a given receptor, as well as by the formation of hetero- and homo-oligomers, which exhibit distinct physiological and pharmacological properties [47]. Most GPCRs are coupled to heterotrimeric $\mathrm{G} \alpha \beta \gamma$ proteins. The $\alpha$-subunits $(\mathrm{G} \alpha)$ are responsible for guanine nucleotide binding and GTP hydrolysis, whereas $\beta \gamma$ subunits form a tightly linked complex [48]. CXCR4 engagement triggers activation of the Goi subfamily, as shown by the ability of pertussis toxin, which uncouples Goi from GPCRs, to block the biological outcomes of CXCR4 activation, including chemotaxis [49-51]. CXCR4 also couples to the $\mathrm{G} \alpha \mathrm{q}$ or $\mathrm{G} \alpha_{12-13}$ subfamilies but the physiological significance of this coupling remains incompletely understood. Indeed, while this coupling was found to activate the migration of $\mathrm{T}$ cell lines or dendritic cells [52,53], it was shown by others to interfere with CXCL12-induced migration of activated $\mathrm{T}$ cells [54].

Upon binding of CXCL12, activated $\mathrm{G} \alpha \beta \gamma$ proteins act on effectors to regulate cellular responses [55]. Effectors include the Src family of tyrosine kinases [56,57] and the phosphoinositide 3-kinase pathways. The latter trigger downstream enzymes including p21-activated kinase and Protein Kinase B/Akt, which are important for the cytoskeletal re-arrangement that takes place during chemotaxis [49,58-60]. In addition, $\mathrm{G} \alpha \beta \gamma$ proteins can activate the phospholipase $\mathrm{C} \beta$, which in turn induces inositol trisphosphate production and intracellular calcium release. These also activate Protein Kinase C, focal adhesion kinase and mitogen-activated protein (MAP) kinase extracellular signal-regulated kinase (ERK) [60-64].
In addition to $G$ protein-dependent activation of effectors, GPCR-promoted signaling may involve interactions with adaptor/scaffolding proteins, which provide specificity and appropriate spatial control of the signaling pathways [65]. Among them, the $\beta$-arrestin proteins have recently emerged as important scaffolds that link GPCRs to the activation of signaling molecules including members of the MAPK family [66], and which ultimately contribute to chemokine receptorinduce chemotaxis [67]. In support of a role for $\beta$ arrestin in CXCL12-dependent chemotaxis, leukocytes from $\beta$-arrestin2-knockout mice display impaired migration in response to CXCL12 [68]. Studies in human cells have demonstrated that $\beta$-arrestin 2 strengthens activation of p38 and ERK/MAPK, leading to CXCL12promoted chemotaxis $[69,70]$. In addition, the $\beta$ arrestin-binding protein filamin, which acts as an adaptor of proteins involved in cytoskeletal reorganization and actin assembly [71,72], participates in regulating the CXCL12-induced activation of the RhoA/ROCK pathway, myosin light chain phosphorylation, cofilin activity and finally chemotaxis [73]. Thus $\beta$-arrestin can fine-tune CXCL12 functions by coupling CXCR4 to different pathways depending upon cellular context.

Another modulator of CXCL12/CXCR4-dependent signaling is the CXCR7 receptor, which was known as RDC1 before its description as a second receptor for CXCL12 [74,75]. CXCR7 and CXCR4 can form heterodimers when co-expressed [76-78]. These heterodimers have pharmacological properties distinct from those of CXCR4 or CXCR7 homodimers [76,77]. Moreover, recent reports suggest that CXCR7 evolved as a decoy receptor that modulates CXCR4 signaling through CXCL12 scavenging [79-81]. Although there is conflicting information as to a direct signaling activity of CXCR7 when triggered by CXCL12, all the reports so far indicate that CXCR7 fails to activate the Goi pathways [82]. However, the recent observation that CXCR7 does activate MAPK through the recruitment of $\beta$-arrestin has suggested that CXCR7 might be a " $\beta$-arrestin-biased" receptor that signals through $\beta$-arrestin in the absence of $\mathrm{G}$ protein activation [83]. This property could explain of how stimulation of CXCR4 or CXCR7 by CXCL12 can lead to distinct physiological outcomes.

\subsection{Regulation of signaling}

CXCL12 also elicits CXCR4 desensitization, an adaptive universal response that avoids persistent receptor stimulation and promotes arrest of $\mathrm{G}$ protein ac- 
Table 1

Alignment of the amino acid sequences of the $\mathrm{C}$-terminus regions of wild type CXCR 4 and the mutants associated with WHIM. The amino acid sequence of the CXCR4 C-terminus region is shown, in which the critical Ser and Thr residues targeted for phosphorylation are underlined and highlighted in red. Sites of premature stop codon or frameshift in the CXCR4 mutant proteins in WHIM patients and the resulting amino acid sequences of the $\mathrm{C}$-terminus are indicated

\begin{tabular}{|c|c|}
\hline Wt CXCR4 & $\begin{array}{lllll}310 & 320 & 330 & 340 & 310 \\
\text { KFKTSAQHALTSVSRGSSLKILSKGKRGGHSSVSTESESSSFHSS }\end{array}$ \\
\hline R334X & KFKTSAQHALTSVSRGSSLKILSKGK \\
\hline G336X & KFKTSAQHALTSVSRGSSLKILSKGKRG \\
\hline S338X & KFKTSAQHALTSVSRGSSLKILSKGKRGGH \\
\hline S339fsX342 & KFKTSAQHALTSVSRGSSLKILSKGKRGGHSCFH \\
\hline E343X & KFKTSAQHALTSVSRGSSLKILSKGKRGGHSSVST \\
\hline G323fsX343 & KFKTSAQHALTSVSRGVQPQDPLQRKARWTFICFH \\
\hline
\end{tabular}

tivation. Desensitization is associated with the rapid phosphorylation of Serine (Ser) and Threonine (Thr) residues of the receptor C-terminus. The phosphorylation is mediated by the second-messenger protein kinase $\mathrm{C}$ or by G-protein-coupled receptor kinases (GRKs), which have unknown specificity [69,84-87]. Recruitment of $\beta$-arrestin to the phosphorylated receptor leads to the internalization of CXCR4 onto early endosomes and sorting of the receptor into lysosomes for proteolysis by an ubiquitin-dependent mechanism [55, 88-90]. G protein-dependent signaling can also be negatively regulated by the Regulators of $\mathrm{G}$ protein Signaling (RGS), which accelerate the intrinsic GTPase activity of $\mathrm{G} \alpha$ subunits [91], and can affect CXCL12mediated $\mathrm{G}$ protein activation and chemotaxis [92-94].

\section{WHIM-associated dysfunctions of CXCL12/CXCR4 signaling}

Familial WHIM syndrome is inherited as an autosomal dominant trait [18]. Sequencing revealed that most patients carry heterozygous mutations in the $C X C R 4$ gene, which was confirmed in additional patients [21, 22]. All six different $C X C R 4$ mutations described so far (Table 1) result in a premature stop codon or a frameshift that eliminates the last 10 to 19 residues of the C-terminus [95]. Deletion of the C-terminus of CXCR4 impairs internalization [84,87] by eliminating the 15 Ser and 3 Thr residues that can be targeted for phosphorylation. Among them, the Ser at positions 324, 325, 338 and 339 appear most criti- cal [85]. Also targeted for phosphorylation are the $\mathrm{Ser}^{341} / \mathrm{Thr}^{342}$ pair, the Ser at position 344 [85] and two clusters localized at the extreme C-terminus of CXCR4 (Ser ${ }^{346} / \mathrm{Ser}^{348}$ and $\mathrm{Ser}^{351} / \mathrm{Ser}^{352}$ ) [96]. Accordingly, CXCR4 mutants characterized in WHIM patients (Table 1), which have deleted most of the critical Ser residues, display impaired internalization [23,95, 97-99]. The residual internalization of CXCR4 mutant receptors could be accounted for by the preserved residues $\mathrm{Ser}^{324} / \mathrm{Ser}^{325}$ [23].

CXCL12-induced internalization of CXCR4 is similarly impaired in leukocytes from two unrelated WHIM patients who carry a wild type $C X C R 4$ gene [23]. The receptor readily internalizes after stimulation of patient leukocytes with the protein kinase $\mathrm{C}$ inducer phorbol ester PMA, thus predicting that the resistance to CXCL12-induced internalization could result from impaired agonist-dependent phosphorylation [23]. To test this possibility, we measured the efficiency of the different GRKs (GRK2, GRK3, GRK5 and GRK6) to facilitate the internalization of CXCR4 in the patients' cells. We observed that expression of GRK3 restores CXCR4 responsiveness, suggesting selective alterations in GRK3 activity in cells from the two patients and an unappreciated role for the kinase in regulating CXCR4 internalization. Indeed, siRNA interference of GRK3 in control cells leads to a marked reduction of receptor internalization, indicating that endogenous GRK2, GRK5 or GRK6 could not compensate for loss of GRK3 [100]. Moreover, the discovery in one patient that altered GRK3 activity results from selectively decreased GSK3 transcripts, provides a likely pathogenic 


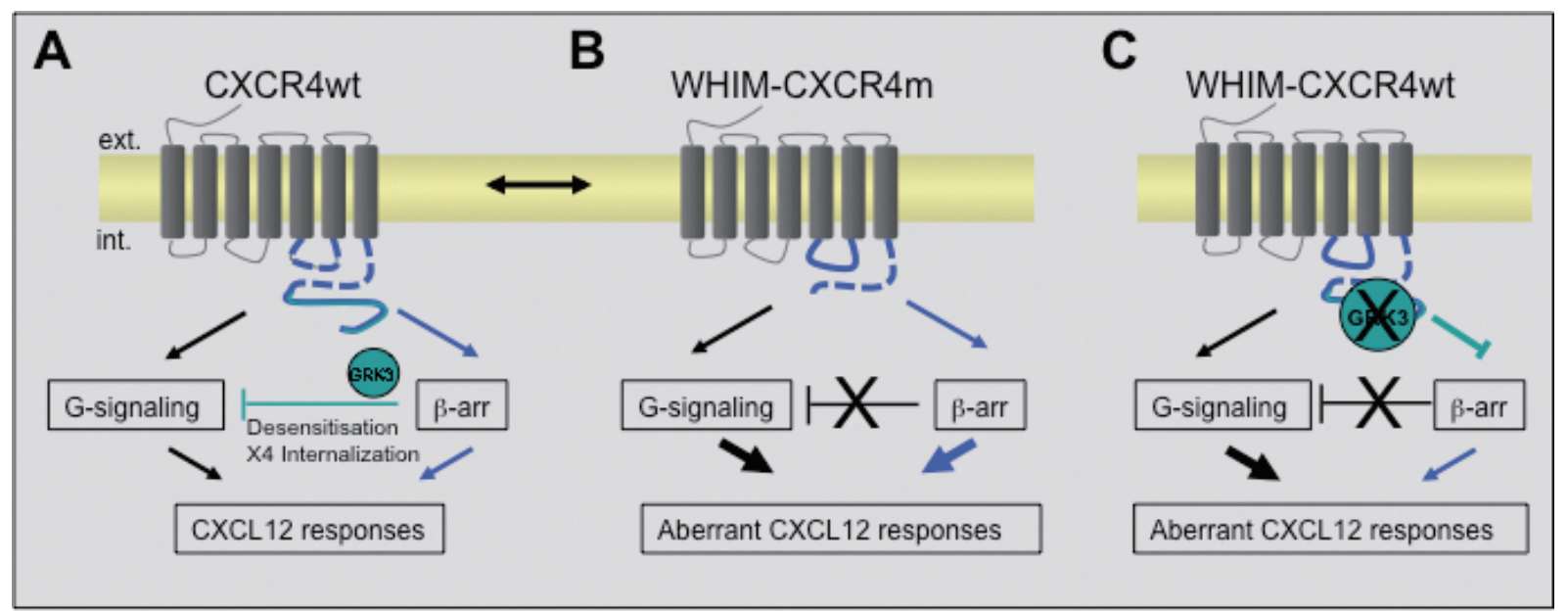

Fig. 1. Normal and aberrant CXCL12/CXCR4-mediated responses. (A) Under normal conditions, CXCL12 responses result from a balance between $\mathrm{G}$ protein activation and $\beta$-arrestins ( $\beta$-arr)-mediated signaling, the latter which involves interactions of $\beta$-arrestins with different domains of the receptor (dashed blue lines). CXCL12 responses are timely controlled by $\beta$-arrestin-mediated desensitization and receptor internalization, which involve interactions of $\beta$-arrestins with the GRK-phosphorylated C-terminus part of the receptor (green/blue bold line). (B) In the WHIM syndrome caused by a mutation in $C X C R 4$, the $\mathrm{C}$-terminus truncated receptor is resistant to CXCL12-induced desensitization and internalization, but remains able to interact with $\beta$-arrestins (due to $\mathrm{C}$-terminus truncations, interactions are favored with domains labeled by bold blue line). Consequently, both deregulated G protein- and $\beta$-arrestin-mediated signaling contribute to aberrant CXCL12 responses. In patient cells, both wild type and mutant receptors are likely co-expressed and may form heterodimers at the cell membrane (line with double-headed arrows). (C) In some cases of WHIM associated with wild type CXCR4, activation of patient cells with CXCL12 does not promote desensitization and CXCR4 internalization as a consequence of GRK3 dysregulation. Therefore, aberrant CXCL12 responses rely on the deregulated G protein-mediated signaling.

mechanism and additional support for a pivotal role for GRK3 in regulating CXCR4 attenuation [100].

Impaired desensitization of CXCR4 is predicted to result in more efficient $\mathrm{G}$ protein activation and improved CXCL12-induced G-protein dependent signals (i.e. calcium mobilization, F-actin polymerization). Nevertheless, the enhanced and prolonged CXCL12 responses featured in the WHIM syndrome (i.e. ERK1/2 signaling, chemotaxis) $[21,23,100,101]$ may also result from aberrant activation of $\beta$-arrestin-dependent pathways (see below) $[98,99]$. As mentioned above, we have ectopically expressed GRK3 in cells from a WHIM patient having a wild type CXCR4 gene and harboring a selective decrease in GRK3 protein. This leads to the normalization not only of the CXCR4 internalization but also of the CXCL12-promoted chemotaxis. Conversely, GRK3 silencing in control cells results in a WHIM-like phenotype (i.e. enhanced CXCL12-promoted chemotaxis) [100]. Our results suggest that GRK3 negatively contributes to the regulation of CXCR4-promoted chemotaxis. An overview of this pathway in normal and WHIM patients is illustrated in Fig. 1.

There is conflicting information regarding the potential of GRK6 to modulate CXCL12-induced chemotaxis. Some reports have found that in mouse, GRK6 plays a positive role in CXCL12-induced migration of $\mathrm{T}$ cells, while others indicated that it plays the opposite role in neutrophils [68,102]. Contribution of GRKs to CXCL12-induced chemotaxis may not only involve the role of the kinases in $\beta$-arrestin-mediated desensitization but also in $\beta$-arrestin-mediated signaling. In support of this last possibility, recent data suggested that $\beta$-arrestin-mediated ERK1/2 signaling requires the phosphorylation of CXCR4 by both GRK3 and GRK6. Whereas GRK3 is proposed to phophorylate the far C-terminus region of CXCR4, the GRK6 kinase was shown by liquid chromatography-tandem mass spectrometry studies to phosphorylate more proximal Ser residues (namely, $\mathrm{Ser}^{324} / \mathrm{Ser}^{325}, \mathrm{Ser}^{330}$ and $\mathrm{Ser}^{339}$ ) [96]. Interestingly, although phosphorylation of the C-terminus of CXCR4 by GRK3 is suggested to increase CXCL12-induced $\beta$-arrestin recruitment to the receptor, phosphorylation by GRK6 had the opposite effects [96]. Overall, these observations suggest some specialization of the GRKs in the regulation of $\beta$ arrestin functions and ultimately in CXCR4 activities.

The regulation of CXCR4 functions exerted by $\beta$ arrestin results from distinct interactions with various regions of the receptor apart from the $\mathrm{C}$-terminus. For instance $\beta$-arrestin-dependent ERK1/2 activation requires interaction of $\beta$-arrestin with the third intracellu- 
lar loop of the receptor [69]. The significance of these observations to the increased CXCL12-induced chemotaxis in WHIM syndrome was recently documented $[98,99]$. Both studies found that WHIM-associated CXCR4 mutants maintain association with $\beta$-arrestins and trigger abnormal $\beta$-arrestin-dependent pathways as revealed by activation of the ERK $1 / 2$ signaling. This occurred despite partial deletion of the C-terminus, which resulted in impaired internalization and desensitization. We initially found that $\beta$-arrestin 2 constitutively interacts with the mutant receptor likely via the third intracellular loop [99]. Latter kinetic studies indicated that the ability of the mutant receptor to interact with $\beta$-arrestin 2 upon CXCL12 addition is delayed as compared to the wild type receptor, thus accounting for the abnormally prolonged CXCL12-induced signaling downstream the mutant receptor [98]. The contribution of this abnormal $\beta$-arrestin 2 signaling to the dysregulation of CXCL12-induced chemotaxis, which is a Goidependent process, requires the presence of the third intracellular loop of the receptor. Altering this loop normalizes cell migration, suggesting that the receptor can concomitantly activate $\beta$-arrestin and G-protein dependent pathways to influence biological function [99] (Fig. 1).

In cells from WHIM patients, mutant receptors functionally prevail over their co-expressed wild type counterparts, suggesting that the mutant receptors alter the functioning of the wild type receptors through a transdominant effect [74]. GPCR exist as oligomers, which can modulate the ability of the receptors to activate signaling pathways $[103,104]$. Extending previous work showing that CXCR4 can form dimers [105-107], we found that mutant and wild type receptors can heterodimerize. Our results suggest that the mutant receptor's ability to aberrantly activate $G$ protein and $\beta$-arrestin pathways is preserved into the heterodimer. These observations might provide a mechanistic basis for the transdominant effect of the mutant receptor, although the significance of this model to the biological dysfunctioning of the CXCL12/CXCR4 axis remains to be investigated in patients' cells.

\section{Conclusions}

A key marker seen in WHIM syndrome is the increased activation of the CXCL12/CXCR4 axis, which usually results from gain-of-function mutations in $C X$ $C R 4$. Investigations into the disease pathogenesis have shed light on mechanisms that tightly control CXCR4 activation and functions. Further characterization of the processes responsible for the enhanced CXCL12induced chemotaxis is needed. In particular, elucidating the role of GRKs and $\beta$-arrestins, which can both terminate and promote signaling, will be informative. Notably, in zebrafish embryos the guided migration of primordial germ cells is controlled by CXCL12 and its receptors. In this model, the C-terminus of CXCR4 was shown to be required for controlling the duration of the migration by downregulation of receptor signaling, and then for precise arrival of the cells at their target [108]. Therefore, setting up related experiments in a mouse model of the WHIM syndrome would be valuable. More extensive studies are also necessary to evaluate the cooperation as well as the selective role of $\beta$-arrestins- and G-protein dependent pathways for CXCL12-induced chemotaxis. It can be anticipated that genetic analysis studies of WHIM patients carrying a wild type $C X C R 4$ gene will permit the identification of alternate genetic causes of the enhanced activity of CXCR4. Interestingly, other pathways might be involved in the pathogenesis of syndromes with WHIMlike features, as recently suggested by the myelokathexis phenotype observed in mice having loss-of-function mutations in the $C x c r 2$ chemokine receptor gene and the phenotype of myelokathexis [109].

Although the immuno-hematological manifestations of the WHIM syndrome apparently result from CXCR4 dysfunctions, the mechanisms by which these dysfunctions might affect leukocyte homeostasis remain unknown. A recent report suggests that the B-cell anomalies, including hypogammaglobulinemia, might result from an impaired trafficking [110] as proposed for the neutropenia and associated myelokathexis defects in neutrophils [111]. However, how CXCL12/CXCR4 dysfunctions predispose WHIM patients to a selective susceptibility to HPV infection is still unknown. WHIM patients generally do not suffer from other viral infections and respond to vaccine antigens. Moreover, recent findings indicate that WHIM patients can develop humoral and cellular immune responses after administration of a tetravalent HPV vaccine [112], making unlikely a selective failure of anti-HPV immunity. HPVs are double-stranded DNA viruses with a tropism for epithelial keratinocytes. We previously described that CXCL12, which is detected neither in keratinocytes of normal epidermis nor in various local and systemic-associated skin pathologies, is expressed in HPV-induced lesions, whether they originate from WHIM patients or not [23]. Whether the CXCL12/CXCR4 axis represents a host susceptibility 
factor for HPV-infection and -associated carcinogenic progression will be interesting to delineate in future studies.

\section{Acknowledgments}

I would like to thank former (K. Balabanian, $\mathrm{K}$. Chow) and actual members (B. Lagane, A. Levoye) of the Pasteur Institute Pathogénie Virale, Inserm U819 laboratory who have contributed to the works and ideas presented in this review and F. Arenzana-Seisdedos for his encouragement and advice. The support provided by grants from INSERM, Assistance PubliqueHôpitaux de Paris, ERA-Net on rare diseases, the Institut national du cancer (InCa), Fondation pour la Recherche Médicale (FRM) and Agence Nationale de la Recherche (ANR) is gratefully acknowledged.

\section{References}

[1] A. Zlotnik, O. Yoshie and H. Nomiyama, The chemokine and chemokine receptor superfamilies and their molecular evolution, Genome Biol 7 (2006), 243.

[2] A. Zlotnik and O. Yoshie, Chemokines: a new classification system and their role in immunity, Immunity 12 (2000), 121127.

[3] T. Nagasawa, H. Kikutani and T. Kishimoto, Molecular cloning and structure of a pre-B-cell growth-stimulating factor, Proc Natl Acad Sci U S A (1994) 91, 2305-2309.

[4] Y. Feng, C.C. Broder, P.E. Kennedy and E.A. Berger, HIV1 entry cofactor: functional cDNA cloning of a seventransmembrane, G protein-coupled receptor, Science (1996) 272, 872-877.

[5] Y.R. Zou, A.H. Kottmann, M. Kuroda, I. Taniuchi and D.R. Littman, Function of the chemokine receptor CXCR4 in haematopoiesis and in cerebellar development, Nature (1998) 393, 595-599.

[6] T. Nagasawa, S. Hirota, K. Tachibana, N. Takakura, S. Nishikawa, Y. Kitamura et al., Defects of B-cell lymphopoiesis and bone-marrow myelopoiesis in mice lacking the CXC chemokine PBSF/SDF-1, Nature 382 (1996), 635638.

[7] Q. Ma, D. Jones, P.R. Borghesani, R.A. Segal, T. Nagasawa, T. Kishimoto et al., Impaired B-lymphopoiesis, myelopoiesis, and derailed cerebellar neuron migration in CXCR4- and SDF-1-deficient mice, Proc Natl Acad Sci U S A 95 (1998), 9448-9453.

[8] C. Martin, P.C. Burdon, G. Bridger, J.C. Gutierrez-Ramos, T.J. Williams and S.M. Rankin, Chemokines acting via CXCR2 and CXCR4 control the release of neutrophils from the bone marrow and their return following senescence, Immunity (2003) 19, 583-593.

[9] C.L. Semerad, F. Liu, A.D. Gregory, K. Stumpf and D.C. Link, G-CSF is an essential regulator of neutrophil trafficking from the bone marrow to the blood, Immunity 17 (2002), 413-423.
[10] W.C. Liles, H.E. Broxmeyer, E. Rodger, B. Wood, K. Hubel, S. Cooper et al., Mobilization of hematopoietic progenitor cells in healthy volunteers by AMD3100, a CXCR4 antagonist, Blood 102 (2003), 2728-2730.

[11] H.E. Broxmeyer, C.M. Orschell, D.W. Clapp, G. Hangoc, S. Cooper, P.A. Plett et al., Rapid mobilization of murine and human hematopoietic stem and progenitor cells with AMD3100, a CXCR4 antagonist, J Exp Med 201 (2005), 1307-1318.

[12] C.C. Bleul, J.L. Schultze and T.A. Springer, B lymphocyte chemotaxis regulated in association with microanatomic localization, differentiation state, and B cell receptor engagement, J Exp Med 187 (1998), 753-762.

[13] A. Corcione, L. Ottonello, G. Tortolina, P. Facchetti, I. Airoldi, R. Guglielmino et al., Stromal cell-derived factor-1 as a chemoattractant for follicular center lymphoma B cells, $J$ Natl Cancer Inst 92 (2000), 628-635.

[14] C.H. Kim and H.E. Broxmeyer, SLC/exodus2/6Ckine/TCA4 induces chemotaxis of hematopoietic progenitor cells: differential activity of ligands of CCR7, CXCR3, or CXCR4 in chemotaxis vs. suppression of progenitor proliferation, $J$ Leukoc Biol 66 (1999), 455-461.

[15] C.C. Bleul, M. Farzan, H. Choe, C. Parolin, I. Clark-Lewis, J. Sodroski et al., The lymphocyte chemoattractant SDF-1 is a ligand for LESTR/fusin and blocks HIV-1 entry, Nature 382 (1996), 829-833.

[16] E. Oberlin, A. Amara, F. Bachelerie, C. Bessia, J.L. Virelizier, F. Arenzana-Seisdedos et al., The CXC chemokine SDF-1 is the ligand for LESTR/fusin and prevents infection by T-cell-line-adapted HIV-1, Nature 382 (1996), 833-835.

[17] A. Muller, B. Homey, H. Soto, N. Ge, D. Catron, M.E. Buchanan et al., Involvement of chemokine receptors in breast cancer metastasis, Nature 410 (2001), 50-56.

[18] P.A. Hernandez, R.J. Gorlin, J.N. Lukens, S. Taniuchi, J. Bohinjec, F. Francois et al., Mutations in the chemokine receptor gene CXCR4 are associated with WHIM syndrome, a combined immunodeficiency disease, Nat Genet 34 (2003), 70-74.

[19] W.W. Zuelzer, "Myelokathexis" - a New Form of Chronic Granulocytopenia. Report of a Case, $N$ Engl J Med 270 (1964), 699-704.

[20] M. Wetzler, M. Talpaz, E.S. Kleinerman, A. King, Y.O. Huh, J.U. Gutterman et al., A new familial immunodeficiency disorder characterized by severe neutropenia, a defective marrow release mechanism, and hypogammaglobulinemia, Am J Med 89 (1990), 663-672.

[21] T. Kawai and H.L. Malech, WHIM syndrome: congenital immune deficiency disease, Curr Opin Hematol 16 (2009), 20-26.

[22] G.A. Diaz and A.V. Gulino, WHIM syndrome: a defect in CXCR4 signaling, Curr Allergy Asthma Rep 5 (2005), 350355.

[23] K. Balabanian, B. Lagane, J.L. Pablos, L. Laurent, T. Planchenault, O. Verola et al., WHIM syndromes with different genetic anomalies are accounted for by impaired CXCR4 desensitization to CXCL12, Blood 105 (2005), 2449-2457.

[24] J.B. Hagan and P.L. Nguyen, WHIM syndrome, Mayo Clin Proc 82 (2007), 1031

[25] D. Sanmun, D. Garwicz, C.I. Smith, J. Palmblad and B. Fadeel, Stromal-derived factor-1 abolishes constitutive apoptosis of WHIM syndrome neutrophils harbouring a truncating CXCR4 mutation, Br J Haematol 134 (2006), 640-644.

[26] M.D. Tarzi, M. Jenner, K. Hattotuwa, A.Z. Faruqi, G.A. Di$\mathrm{az}$ and H.J. Longhurst, Sporadic case of warts, hypogam- 
maglobulinemia, immunodeficiency, and myelokathexis syndrome, J Allergy Clin Immunol 116 (2005), 1101-1105.

[27] B. Weston, R.A. Axtell, E.F. Todd, 3rd., M. Vincent, K.J Balazovich, S.J. Suchard et al., Clinical and biologic effects of granulocyte colony stimulating factor in the treatment of myelokathexis, J Pediatr 118 (1991), 229-234.

[28] M. Wetzler, M. Talpaz, M.J. Kellagher, J.U. Gutterman and R. Kurzrock, Myelokathexis: normalization of neutrophil counts and morphology by GM-CSF, JAMA 267 (1992), 2179-2180.

[29] J. Bohinjec and D. Andoljsek, Neutrophil-releasing activity of recombinant human granulocyte-macrophage colony stimulating factor in myelokathexis, Br J Haematol 82 (1992), 169-170.

[30] A.V. Gulino, WHIM syndrome: a genetic disorder of leukocyte trafficking, Curr Opin Allergy Clin Immunol 3 (2003), 443-450.

[31] G.A. Diaz, CXCR4 mutations in WHIM syndrome: a misguided immune system? Immunol Rev 203 (2005), 235-243.

[32] L.D. Notarangelo and R. Badolato, Leukocyte trafficking in primary immunodeficiencies, J Leukoc Biol 85 (2009), 335343.

[33] K. Palczewski, G protein-coupled receptor rhodopsin, Annu Rev Biochem 75 (2006), 743-767.

[34] M.J. Serrano-Vega, F. Magnani, Y. Shibata and C.G. Tate, Conformational thermostabilization of the beta1-adrenergic receptor in a detergent-resistant form, Proc Natl Acad Sci U $S A 105$ (2008), 877-882.

[35] S.G. Rasmussen, H.J. Choi, D.M. Rosenbaum, T.S. Kobilka, F.S. Thian, P.C. Edwards et al., Crystal structure of the human beta2 adrenergic G-protein-coupled receptor, Nature 450 (2007), 383-387.

[36] M.P. Crump, J.H. Gong, P. Loetscher, K. Rajarathnam, A. Amara, F. Arenzana-Seisdedos et al., Solution structure and basis for functional activity of stromal cell-derived factor-1; dissociation of CXCR4 activation from binding and inhibition of HIV-1, Embo J 16 (1997), 6996-7007.

[37] E.K. Gozansky, J.M. Louis, M. Caffrey and G.M. Clore, Mapping the binding of the N-terminal extracellular tail of the CXCR4 receptor to stromal cell-derived factor-1alpha, $J$ Mol Biol 345 (2005), 651-658.

[38] Y. Ohnishi, T. Senda, N. Nandhagopal, K. Sugimoto, T. Shioda, Y. Nagal et al., Crystal structure of recombinant native SDF-1alpha with additional mutagenesis studies: an attempt at a more comprehensive interpretation of accumulated structure-activity relationship data, J Interferon Cytokine Res 20 (2000), 691-700.

[39] J.W. Murphy, Y. Cho, A. Sachpatzidis, C. Fan, M.E. Hodsdon and E. Lolis, Structural and functional basis of CXCL12 (stromal cell-derived factor-1 alpha) binding to heparin, $J$ Biol Chem 282 (2007), 10018-10027.

[40] A. Brelot, N. Heveker, M. Montes and M. Alizon, Identification of residues of CXCR4 critical for human immunodeficiency virus coreceptor and chemokine receptor activities, J Biol Chem 275 (2000), 23736-23744.

[41] N. Zhou, Z. Luo, J. Luo, D. Liu, J.W. Hall, R.J. Pomerantz et al., Structural and functional characterization of human CXCR4 as a chemokine receptor and HIV-1 co-receptor by mutagenesis and molecular modeling studies, J Biol Chem 276 (2001), 42826-42833.

[42] B.J. Doranz, S.S. Baik and R.W. Doms, Use of a gp120 binding assay to dissect the requirements and kinetics of human immunodeficiency virus fusion events, J Virol 73 (1999), 10346-10358.
[43] C.T. Veldkamp, C. Seibert, F.C. Peterson, N.B. De la Cruz, J.C. Haugner, 3rd., H. Basnet et al., Structural basis of CXCR4 sulfotyrosine recognition by the chemokine SDF1/CXCL12, Sci Signal 1 (2008), ra4.

[44] D. Schols, J.A. Este, G. Henson and E. De Clercq, Bicyclams, a class of potent anti-HIV agents, are targeted at the HIV coreceptor fusin/CXCR-4, Antiviral Res 35 (1997), 147-156.

[45] L.O. Gerlach, R.T. Skerlj, G.J. Bridger and T.W. Schwartz, Molecular interactions of cyclam and bicyclam non-peptide antagonists with the CXCR4 chemokine receptor, J Biol Chem 276 (2001), 14153-14160.

[46] Y. Kofuku, C. Yoshiura, T. Ueda, H. Terasawa, T. Hirai, S. Tominaga et al., Structural basis of the interaction between chemokine stromal cell-derived factor-1/CXCL12 and its Gprotein-coupled receptor CXCR4, J Biol Chem 284 (2009), 35240-35250.

[47] K. Defea, Beta-arrestins and heterotrimeric G-proteins: collaborators and competitors in signal transduction, $\mathrm{Br} J$ Pharmacol 153(Suppl 1) (2008), S298-S309.

[48] A.G. Gilman, G proteins: transducers of receptor-generated signals, Аппи Rev Biochem 56 (1987), 615-649.

[49] Y. Sotsios, G.C. Whittaker, J. Westwick and S.G. Ward, The CXC chemokine stromal cell-derived factor activates a Gicoupled phosphoinositide 3-kinase in T lymphocytes, $\mathrm{J}$ Immunol 163 (1999), 5954-5963.

[50] S. Ortolano, I.Y. Hwang, S.B. Han and J.H. Kehrl, Roles for phosphoinositide 3-kinases, Bruton's tyrosine kinase, and Jun kinases in B lymphocyte chemotaxis and homing, Eur J Immunol 36 (2006), 1285-1295.

[51] M. Thelen, Dancing to the tune of chemokines, Nat Immunol 2 (2001), 129-134.

[52] W. Tan, D. Martin and J.S. Gutkind, The Galpha13-Rho signaling axis is required for SDF-1-induced migration through CXCR4, J Biol Chem 281 (2006), 39542-39549.

[53] G. Shi, S. Partida-Sanchez, R.S. Misra, M. Tighe, M.T. Borchers, J.J. Lee et al., Identification of an alternative $\mathrm{G}\{$ alpha $\}$ q-dependent chemokine receptor signal transduction pathway in dendritic cells and granulocytes, $J$ Exp Med 204 (2007), 2705-2718.

[54] B. Molon, G. Gri, M. Bettella, C. Gomez-Mouton, A. Lanzavecchia, A.C. Martinez et al., T cell costimulation by chemokine receptors, Nat Immunol 6 (2005), 465-471.

[55] J.M. Busillo and J.L. Benovic, Regulation of CXCR4 signaling, Biochim Biophys Acta 1768 (2007), 952-963.

[56] H.Y. Liu, G.B. Wen, J. Han, T. Hong, D. Zhuo, Z. Liu et al., Inhibition of gluconeogenesis in primary hepatocytes by stromal cell-derived factor-1 (SDF-1) through a c-Src/Aktdependent signaling pathway, J Biol Chem 283 (2008), 30642-30649.

[57] M. Wysoczynski, M. Kucia, J. Ratajczak and M.Z. Ratajczak, Cleavage fragments of the third complement component (C3) enhance stromal derived factor-1 (SDF-1)-mediated platelet production during reactive postbleeding thrombocytosis, Leukemia 21 (2007), 973-982.

[58] N. Volinsky, A. Gantman and D. Yablonski, A Pak- and Pixdependent branch of the SDF-1alpha signalling pathway mediates $\mathrm{T}$ cell chemotaxis across restrictive barriers, Biochem J 397 (2006), 213-222.

[59] G.M. Fuhler, A.L. Drayer, S.G. Olthof, J.J. Schuringa, P.J. Coffer and E. Vellenga, Reduced activation of protein kinase $\mathrm{B}$, Rac, and F-actin polymerization contributes to an impairment of stromal cell derived factor-1 induced migration of CD34+ cells from patients with myelodysplasia, Blood 111 (2008), 359-368. 
[60] B. Tilton, L. Ho, E. Oberlin, P. Loetscher, F. Baleux, I. Clark-Lewis et al., Signal transduction by CXC chemokine receptor 4. Stromal cell-derived factor 1 stimulates prolonged protein kinase B and extracellular signal-regulated kinase 2 activation in T lymphocytes, J Exp Med 192 (2000), 313-324.

[61] A.M. Glodek, Y. Le, D.M. Dykxhoorn, S.Y. Park, G. Mostoslavsky, R. Mulligan et al., Focal adhesion kinase is required for CXCL12-induced chemotactic and pro-adhesive responses in hematopoietic precursor cells, Leukemia 21 (2007), 1723-1732.

[62] R.K. Ganju, S.A. Brubaker, J. Meyer, P. Dutt, Y. Yang, S. Qin et al., The alpha-chemokine, stromal cell-derived factor-1alpha, binds to the transmembrane G-protein-coupled CXCR-4 receptor and activates multiple signal transduction pathways, J Biol Chem 273 (1998), 23169-23175.

[63] J.F. Wang, I.W. Park and J.E. Groopman, Stromal cell-derived factor-1alpha stimulates tyrosine phosphorylation of multiple focal adhesion proteins and induces migration of hematopoietic progenitor cells: roles of phosphoinositide-3 kinase and protein kinase C, Blood 95 (2000), 2505-2513.

[64] Y. Le, M. Honczarenko, A.M. Glodek, D.K. Ho and L.E. Silberstein, CXC chemokine ligand 12-induced focal adhesion kinase activation and segregation into membrane domains is modulated by regulator of $\mathrm{G}$ protein signaling 1 in pro-B cells, J Immunol 174 (2005), 2582-2590.

[65] K.L. Pierce, R.T. Premont and R.J. Lefkowitz, Seventransmembrane receptors, Nat Rev Mol Cell Biol 3 (2002), 639-650.

[66] L.M. Luttrell and R.J. Lefkowitz, The role of beta-arrestins in the termination and transduction of G-protein-coupled receptor signals, J Cell Sci 115 (2002), 455-465.

[67] K.A. Defea, Stop That Cell! beta-Arrestin-Dependent Chemotaxis: A Tale of Localized Actin Assembly and Receptor Desensitization, Annu Rev Physiol 69 (2007), 535560.

[68] A.M. Fong, R.T. Premont, R.M. Richardson, Y.R. Yu, R.J. Lefkowitz and D.D. Patel, Defective lymphocyte chemotaxis in beta-arrestin2- and GRK6-deficient mice, Proc Natl Acad Sci U S A 99 (2002), 7478-7483.

[69] Z.J. Cheng, J. Zhao, Y. Sun, W. Hu, Y.L. Wu, B. Cen et al., beta-arrestin differentially regulates the chemokine receptor CXCR4-mediated signaling and receptor internalization, and this implicates multiple interaction sites between betaarrestin and CXCR4, J Biol Chem 275 (2000), 2479-2485.

[70] Y. Sun, Z. Cheng, L. Ma and G. Pei, Beta-arrestin2 is critically involved in CXCR4-mediated chemotaxis, and this is mediated by its enhancement of p38 MAPK activation, J Biol Chem 277 (2002), 49212-49219.

[71] K.M. Kim, R.R. Gainetdinov, S.A. Laporte, M.G. Caron and L.S. Barak, G protein-coupled receptor kinase regulates dopamine D3 receptor signaling by modulating the stability of a receptor-filamin-beta-arrestin complex. A case of autoreceptor regulation, J Biol Chem 280 (2005), 12774-12780.

[72] M.G. Scott, V. Pierotti, H. Storez, E. Lindberg, A. Thuret, O. Muntaner et al., Cooperative regulation of extracellular signal-regulated kinase activation and cell shape change by filamin A and beta-arrestins, Mol Cell Biol 26 (2006), 34323445 .

[73] S. Jimenez-Baranda, C. Gomez-Mouton, A. Rojas, L. Martinez-Prats, E. Mira, R. Ana Lacalle et al., Filamin-A regulates actin-dependent clustering of HIV receptors, Nat Cell Biol 9 (2007), 838-846.

[74] K. Balabanian, B. Lagane, S. Infantino, K.Y. Chow, J. Harriague, B. Moepps et al., The chemokine SDF-1/CXCL12 binds to and signals through the orphan receptor RDC1 in $\mathrm{T}$ lymphocytes, J Biol Chem 280 (2005), 35760-35766.

[75] J.M. Burns, B.C. Summers, Y. Wang, A. Melikian, R. Berahovich, Z. Miao et al., A novel chemokine receptor for SDF-1 and I-TAC involved in cell survival, cell adhesion, and tumor development, J Exp Med 203 (2006), 2201-2213.

[76] F. Sierro, C. Biben, L. Martinez-Munoz, M. Mellado, R.M. Ransohoff, M. Li et al., Disrupted cardiac development but normal hematopoiesis in mice deficient in the second CXCL12/SDF-1 receptor, CXCR7, Proc Natl Acad Sci U S A 104 (2007), 14759-14764.

[77] A. Levoye, K. Balabanian, F. Baleux, F. Bachelerie and B. Lagane, CXCR7 heterodimerizes with CXCR4 and regulates CXCL12-mediated G protein signaling, Blood 113 (2009), 6085-6093.

[78] K.E. Luker, M. Gupta and G.D. Luker, Imaging chemokine receptor dimerization with firefly luciferase complementation, FASEB J 23 (2009), 823-834.

[79] B. Boldajipour, H. Mahabaleshwar, E. Kardash, M. Reichman-Fried, H. Blaser, S. Minina et al., Control of chemokine-guided cell migration by ligand sequestration, Cell 132 (2008), 463-473.

[80] C. Dambly-Chaudiere, N. Cubedo and A. Ghysen, Control of cell migration in the development of the posterior lateral line: antagonistic interactions between the chemokine receptors CXCR4 and CXCR7/RDC1, BMC Dev Biol 7 (2007), 23.

[81] U. Naumann, E. Cameroni, M. Pruenster, H. Mahabaleshwar, E. Raz, H.G. Zerwes et al., CXCR7 functions as a scavenger for CXCL12 and CXCL11, PLoS One 5 (2010), e9175.

[82] M. Thelen and S. Thelen, CXCR7, CXCR4 and CXCL12: an eccentric trio? J Neuroimmunol 198 (2008), 9-13.

[83] S. Rajagopal, J. Kim, S. Ahn, S. Craig, C.M. Lam, N.P. Gerard et al., Beta-arrestin- but not $\mathrm{G}$ protein-mediated signaling by the "decoy" receptor CXCR7, Proc Natl Acad Sci U S A 107 (2010), 628-632.

[84] B. Haribabu, R.M. Richardson, I. Fisher, S. Sozzani, S.C. Peiper, R. Horuk et al., Regulation of human chemokine receptors CXCR4. Role of phosphorylation in desensitization and internalization, J Biol Chem 272 (1997), 28726-28731.

[85] M.J. Orsini, J.L. Parent, S.J. Mundell, J.L. Benovic and A. Marchese, Trafficking of the HIV coreceptor CXCR4. Role of arrestins and identification of residues in the c-terminal tail that mediate receptor internalization, J Biol Chem 274 (1999), 31076-31086.

[86] N. Signoret, M.M. Rosenkilde, P.J. Klasse, T.W. Schwartz, M.H. Malim, J.A. Hoxie et al., Differential regulation of CXCR4 and CCR5 endocytosis, J Cell Sci 111 (Pt 18) (1998), 2819-2830.

[87] N. Signoret, J. Oldridge, A. Pelchen-Matthews, P.J. Klasse, T. Tran, L.F. Brass et al., Phorbol esters and SDF-1 induce rapid endocytosis and down modulation of the chemokine receptor CXCR4, J Cell Biol 139 (1997), 651-664.

[88] A. Marchese, C. Raiborg, F. Santini, J.H. Keen, H. Stenmark and J.L. Benovic, The E3 ubiquitin ligase AIP4 mediates ubiquitination and sorting of the $\mathrm{G}$ protein-coupled receptor CXCR4, Dev Cell 5 (2003), 709-722.

[89] A. Marchese and J.L. Benovic, Agonist-promoted ubiquitination of the $\mathrm{G}$ protein-coupled receptor CXCR4 mediates lysosomal sorting, J Biol Chem 276 (2001), 45509-45512.

[90] R. Malik and A. Marchese, Arrestin-2 Interacts with the ESCRT Machinery to Modulate Endosomal Sorting of CXCR4, Mol Biol Cell, 21 (2010), 2529-2541.

[91] N. Watson, M.E. Linder, K.M. Druey, J.H. Kehrl and K.J. Blumer, RGS family members: GTPase-activating pro- 
teins for heterotrimeric G-protein alpha-subunits, Nature $\mathbf{3 8 3}$ (1996), 172-175.

[92] J.D. Estes, T.C. Thacker, D.L. Hampton, S.A. Kell, B.F. Keele, E.A. Palenske et al., Follicular dendritic cell regulation of CXCR4-mediated germinal center CD4 T cell migration, J Immunol 173 (2004), 6169-6178.

[93] G.X. Shi, K. Harrison, G.L. Wilson, C. Moratz and J.H. Kehrl, RGS13 regulates germinal center B lymphocytes responsiveness to CXC chemokine ligand (CXCL) 12 and CXCL13, J Immunol 169 (2002), 2507-2515.

[94] M. Berthebaud, C. Riviere, P. Jarrier, A. Foudi, Y. Zhang, D. Compagno et al., RGS16 is a negative regulator of SDF1-CXCR4 signaling in megakaryocytes, Blood 106 (2005), 2962-2968.

[95] L. Tassone, L.D. Notarangelo, V. Bonomi, G. Savoldi, A. Sensi, A. Soresina et al., Clinical and genetic diagnosis of warts, hypogammaglobulinemia, infections, and myelokathexis syndrome in 10 patients, J Allergy Clin Immunol 123 (2009), 1170-1173, 3 e1-e3.

[96] J.M. Busillo, S. Armando, R. Sengupta, O. Meucci, M. Bouvier and J.L. Benovic, Site-specific phosphorylation of CXCR4 is dynamically regulated by multiple kinases and results in differential modulation of CXCR4 signaling, $\mathrm{J}$ Biol Chem 285 (2010), 7805-7817.

[97] T. Kawai, U. Choi, N.L. Whiting-Theobald, G.F. Linton, S. Brenner, J.M. Sechler et al., Enhanced function with decreased internalization of carboxy-terminus truncated CXCR4 responsible for WHIM syndrome, Exp Hematol 33 (2005), 460-468.

[98] P.J. McCormick, M. Segarra, P. Gasperini, A.V. Gulino and G. Tosato, Impaired recruitment of Grk6 and beta-Arrestin 2 causes delayed internalization and desensitization of a WHIM syndrome-associated CXCR4 mutant receptor, PLoS One 4 (2009), e8102.

[99] B. Lagane, K.Y. Chow, K. Balabanian, A. Levoye, J. Harriague, T. Planchenault et al., CXCR4 dimerization and betaarrestin-mediated signaling account for the enhanced chemotaxis to CXCL12 in WHIM syndrome, Blood 112 (2008), 34-44.

[100] K. Balabanian, A. Levoye, L. Klemm, B. Lagane, O. Hermine, J. Harriague et al., Leukocyte analysis from WHIM syndrome patients reveals a pivotal role for GRK3 in CXCR4 signaling, J Clin Invest 118 (2008), 1074-1084.

[101] A.V. Gulino, D. Moratto, S. Sozzani, P. Cavadini, K. Otero, L. Tassone et al., Altered leukocyte response to CXCL12 in patients with warts hypogammaglobulinemia, infections, myelokathexis (WHIM) syndrome, Blood 104 (2004), 444452 .
[102] A. Vroon, C.J. Heijnen, R. Raatgever, I.P. Touw, R.E. Ploemacher, R.T. Premont et al., GRK6 deficiency is associated with enhanced CXCR4-mediated neutrophil chemotaxis in vitro and impaired responsiveness to $\mathrm{G}-\mathrm{CSF}$ in vivo, J Leukoc Biol 75 (2004), 698-704.

[103] M.J. Lohse, Dimerization in GPCR mobility and signaling, Curr Opin Pharmacol 10 (2010), 53-58.

[104] G. Milligan, G protein-coupled receptor hetero-dimerization: contribution to pharmacology and function, Br J Pharmacol 158 (2009), 5-14.

[105] G.J. Babcock, M. Farzan and J. Sodroski, Ligandindependent dimerization of CXCR4, a principal HIV-1 coreceptor, J Biol Chem 278 (2003), 3378-3385.

[106] Y.A. Berchiche, K.Y. Chow, B. Lagane, M. Leduc, Y. Percherancier, N. Fujii et al., Direct assessment of CXCR4 mutant conformations reveals complex link between receptor structure and G(alpha)(i) activation, J Biol Chem 282 (2007), 5111-5115.

[107] Y. Percherancier, Y.A. Berchiche, I. Slight, R. VolkmerEngert, H. Tamamura, N. Fujii et al., Bioluminescence resonance energy transfer reveals ligand-induced conformational changes in CXCR4 homo- and heterodimers, J Biol Chem 280 (2005), 9895-9903.

[108] S. Minina, M. Reichman-Fried and E. Raz, Control of receptor internalization, signaling level, and precise arrival at the target in guided cell migration, Curr Biol 17 (2007), 11641172

[109] K.J. Eash, A.M. Greenbaum, P.K. Gopalan and D.C. Link, CXCR2 and CXCR4 antagonistically regulate neutrophil trafficking from murine bone marrow, J Clin Invest 120 (2010), 2423-2431.

[110] P.J. Mc Guire, C. Cunningham-Rundles, H. Ochs and G.A. Diaz, Oligoclonality, impaired class switch and B-cell memory responses in WHIM syndrome, Clin Immunol 135 (2010), 412-421.

[111] T. Kawai, U. Choi, L. Cardwell, S.S. DeRavin, N. Naumann, N.L. Whiting-Theobald et al., WHIM syndrome myelokathexis reproduced in the NOD/SCID mouse xenotransplant model engrafted with healthy human stem cells transduced with C-terminus-truncated CXCR4, Blood 109 (2007), 78-84.

[112] A. Handisurya, C. Schellenbacher, B. Reininger, F. Koszik, P. Vyhnanek, A. Heitger et al., A quadrivalent HPV vaccine induces humoral and cellular immune responses in WHIM immunodeficiency syndrome, Vaccine 28 (2010), 4837-4841. 


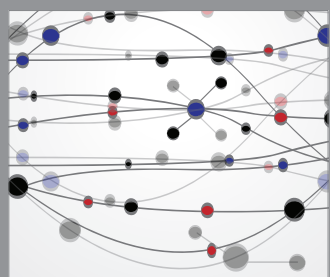

The Scientific World Journal
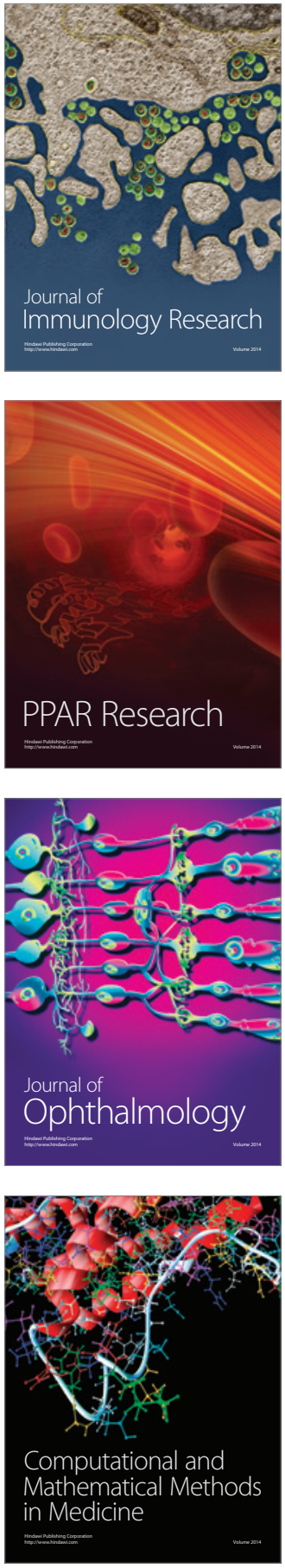

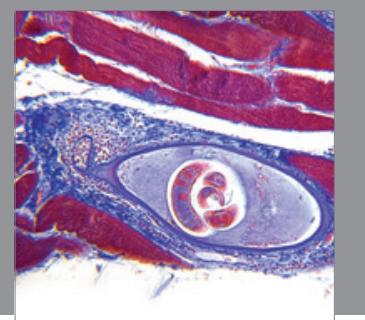

Gastroenterology

Research and Practice
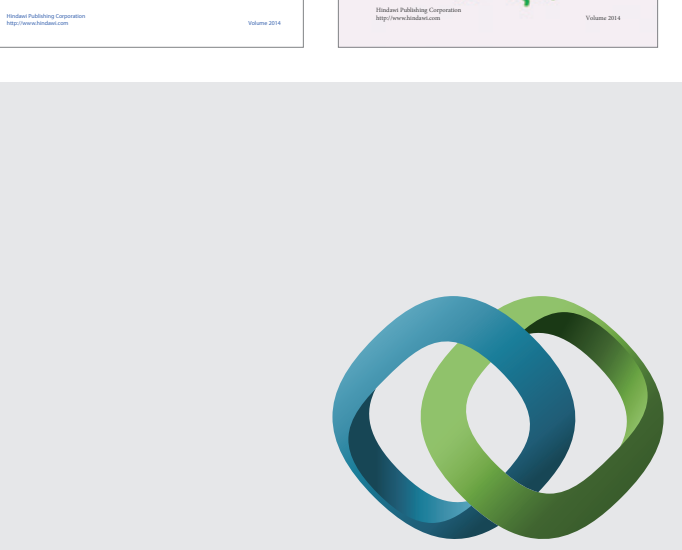

\section{Hindawi}

Submit your manuscripts at

http://www.hindawi.com
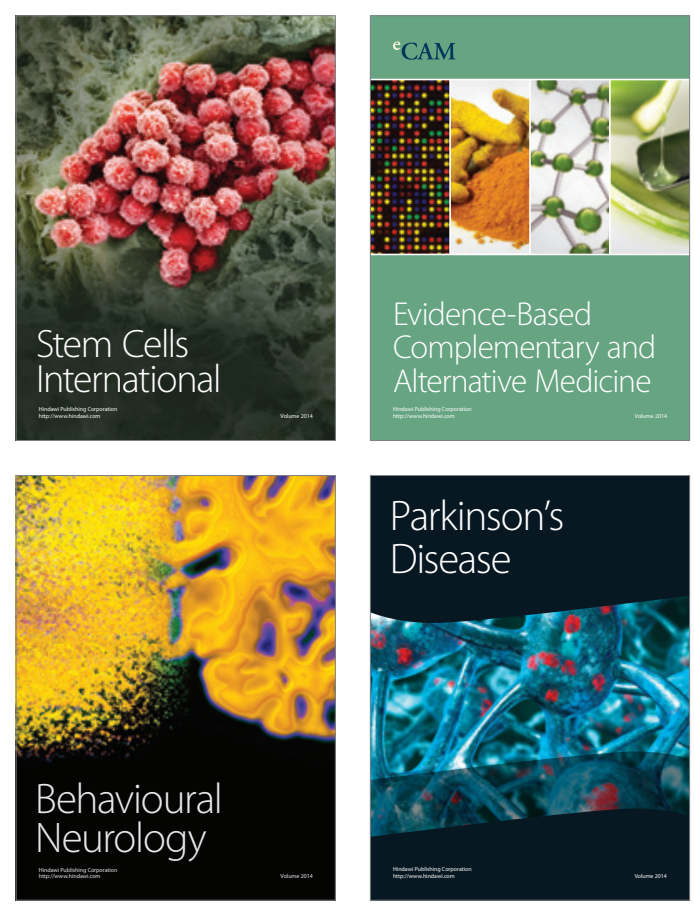

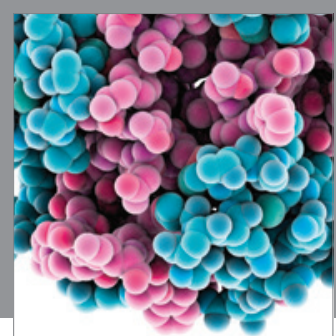

Journal of
Diabetes Research

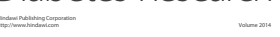

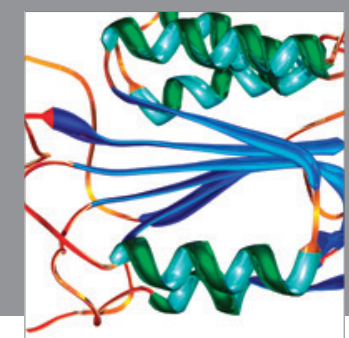

Disease Markers
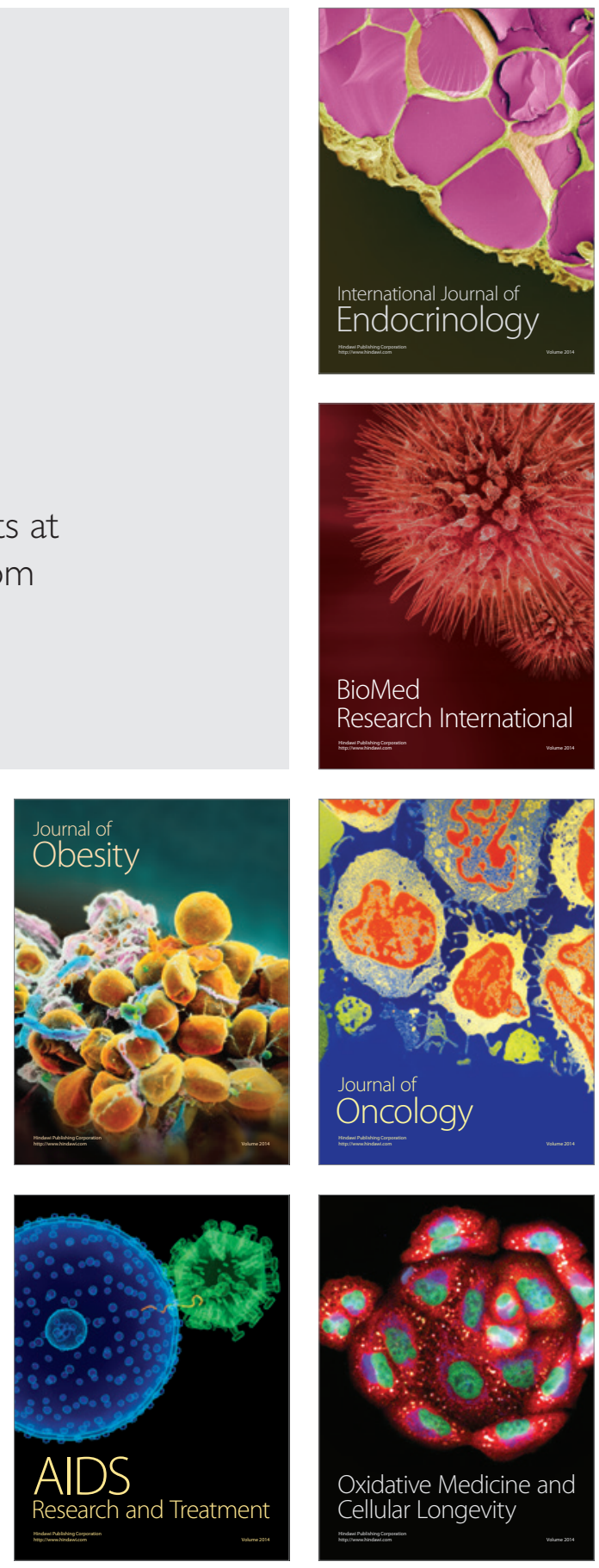